\title{
The effect of shaft diameter on the surface quality in turning machine for different sets of cutting parameter
}

\author{
Saif Abdullah Al-Mahrouqi \\ Adeel H. Suhail \\ MIDDLE EAST COLLEGE \\ Middle East College
}

In the manufacturing industry, machining is the process which has been used widely within the industry for carrying out various operations. By putting the materials together, mechanical parts can be formed with the help of raw materials change and these mechanical parts used in the formation of heavy and small machineries for the personal used and for the industrial use as well.

Most of the metals are being manufactured with the help of machining. In the process of turning, the cutting parameters gained the opportunity to increase productivity. However, there also exists a consequence regarding the quality and deterioration risk and the life of the tool which need to be controlled to achieve greater efficiencies.

The selection of parameters is based on the materials used in workpiece, tools, and other stuff. Additionally, the size of the tool matters as well, therefore it should also be selected carefully by keeping in mind the need of the machine and capability of the users regarding managing that machine. Many factors could affect the machining performance and during turning process, workpiece diameter could be one of these factors which affect the surface quality. The main objective of this study is to investigate the role of shaft diameter on the surface quality in Lathe turning machine. Taguchi method and Analysis Of Variance (ANOVA) were used for data analysis and to optimize the cutting parameters with several experimental runs well designed. The result shows the shaft diameter effect quality of workpiece surface and the researchers should take into account this effect during their study and compare it with other researcher results.

\section{Introduction}

The Introduction should be succinct, with no subheadings, and should present the background information necessary to provide appropriate context for the results. Format is simple font size $9 \mathrm{pt}$ suing only Times New Roman

Machining is responsible to perform cutting operations, due to the reason the various equipment is used. Drilling machines, lathe machine, milling machines and other tools are used for cutting operations and these machines have made the cutting operations more easy which were never before. The invention of such machineries started with the industrial revolution and these machines become the integral part of the industrial processes. Despite the cutting operations, the shaping of the metals is one of the crucial steps, which can be done by using turning process and these steps performed with great care as little negligence could create adverse results. It is noted that the invention of such machines has increased productivity and performances for its users at each level and has become the major prospect of attaining prosperous growth. Furthermore, these machines also helped business to reduce the cost and it is expected that reduction in the cost of manufacturing could increase the chances of a successful business with providing clear edge to its users over the businesses and firms who has not engaged such machineries into their business processes. 


\section{Journal of Student Research}

Fourth Middle East College Student Research Conference, Muscat, Sultanate of Oman

There are many researches were study the effect of many different factors on machining quality and the cutting parameter optimization, cutting factors presented a study for cutting parameter optimization in turning process.

The study of (Bhuiyan, and Ahmed, 2014) divided into two parts. The first part discussed the model formulation which is essential for determining the optimization of cutting parameters and the second part is the computational methodology. The model formulation part describes the Response Surface Methodology (RSM) and the computational methodology describes the genetic algorithm approach the methods of response surface are found to be successful to implement the trend analysis of cutting force. It also includes the combinations of design variables such as feed rate, depth of the cut and cutting speed.

This research study is focused to present the cutting force of AISI 1040 steel and develop a model of the main cutting force, and in order to calculate the optimized cutting parameters and improve the surface finish, the researcher has used a number of artificial intelligence algorithms. These algorithms work together with the RSM to get the optimal results.

The research conducted by Sahu, Sahu, and Dubey (2017), is using the Taguchi method for optimizing the machining parameters. In addition to this, it has also been observed that it minimizes the number of experiments. Furthermore, this method is also used to determine the relationship between changes in the hardness on the surface of the material caused by the turning operation. Moreover, the changes in the hardness are also determined with respect to the certain machining parameters such as depth of the cut, feed rate and speed of the spindle. There are a number of experiments involved along with the steps of Taguchi method that have been performed on the material. The operation is carried out on mild steel using the lathe machine. High-speed steel is used as the cutting tool In addition to this; ANOVA analysis is conducted to test the facing process and surface roughness of turning.

It is evident from the study conducted that a spindle speed of $35 \mathrm{~m} / \mathrm{min}$, depth cut of $1.25 \mathrm{~mm}$ and a feed rate of $0.15 \mathrm{~mm} / \mathrm{rev}$ is considered to be the best surface finish characteristics. In addition to this, by observing the levels of Taguchi parameter design, it has been noted that optimum parameter levels were also the same.

This study presented by (Adeel et al, 2010) to optimize the cutting parameters using two performance measures, workpiece surface temperature and surface roughness. Optimal cutting parameters for each performance measure were obtained employing Taguchi techniques. The orthogonal array, signal to noise ratio and analysis of variance were employed to study the performance characteristics in turning operation. Taguchi and Analysis Of Variance (ANOVA) can conveniently optimize the cutting parameters with several experimental runs well designed. Taguchi parameter can optimize the performance and reduce the system performance. ANOVA used to identify significant variables and interaction effect.

The cutting speed, feed rate and depth of cut selected to analyses effect of surface roughness and workpiece temperature. The experimental results showed that the workpiece surface temperature can be sensed and used effectively as an indicator to control the cutting performance and improves the optimization process. Thus, it is possible to increase machine utilization and decrease production cost in an automated manufacturing environment.

The average surface roughness ( $\mathrm{Ra}$ ) represents a measure of the surface quality, and it is mostly influenced by the cutting speed, the feed rate, and the depth of cut. Quantifying the relationship between surface roughness and cutting parameters is a very important task. In the study presented by (Dejan Tanikić, 2010) regression analysis was used for modelling and optimization of the surface roughness in dry single-point turning of the alloyed steel, using coated tungsten carbide inserts. The experiment has been designed and carried out on the basis of a three-level full factorial design. The linear, the quadratic and the power (non-linear) mathematical models were selected for the 


\section{Journal of Student Research}

Fourth Middle East College Student Research Conference, Muscat, Sultanate of Oman

analysis. Obtained results are in good accordance with the experimentally obtained data, confirming the effectiveness of regression analysis in modelling and optimization of surface roughness in the turning process. The general conclusion is that the surface roughness has a clear downward trend with the cutting speed increase and decrease in the feed rate and the depth of cut.

Many factors could affect the machining performance and during turning process, workpiece diameter could be one of these factors which affect the surface quality. The main objective of the current study is to investigate the role of shaft diameter on the surface quality in lathe turning machine. Taguchi method and Analysis Of Variance (ANOVA) were used for data analysis and to optimize the cutting parameters with several experimental runs well designed.

\section{Research Methodology}

In this study (Lath turning machine) has been used for mild steel AISI2010 machining. The selected diameter sizes are $20 \mathrm{~mm}, 30 \mathrm{~mm}$ and $50 \mathrm{~mm}$. workpiece was $200 \mathrm{~mm}$ in length prepared using Hacksaw cutting machine, then turning the shaft from both sides in order to take surface roughness. By using surface roughness tester three reading for each set of cutting parameters were measured, and the average of them was calculated. Different cutting tool In each turning used in order to find accurate results and prevent the tools wear. During turning process three input parameter will be considered speed, feed and depth of cut.

Three levels for each parameter are selected as shown in Table 1.

\begin{tabular}{|l|l|l|}
\hline Cutting Speed (RPM) & Feed Rate $(\mathrm{mm} / \mathrm{Rev})$ & Depth of Cut $(\mathrm{mm})$ \\
\hline 755 & 0.5 & 0.5 \\
\hline 1255 & 1.0 & 1.0 \\
\hline 2000 & 1.5 & 1.6 \\
\hline
\end{tabular}

Table 1. Cutting Parameter levels

The total sets of the experimental tests shown in table 2 below:

\begin{tabular}{|l|l|l|l|}
\hline Shaft Diameter & Cutting Speed & Feed Rate & Depth of Cut \\
\hline 20 & 755 & 0.5 & 0.5 \\
\hline 20 & 755 & 0.5 & 1.0 \\
\hline 20 & 755 & 0.5 & 1.6 \\
\hline 30 & 755 & 1.0 & 0.5 \\
\hline 30 & 755 & 1.0 & 1.0 \\
\hline 30 & 755 & 1.0 & 1.6 \\
\hline 50 & 755 & 1.5 & 0.5 \\
\hline 50 & 755 & 1.5 & 1.0 \\
\hline 50 & 755 & 1.5 & 1.6 \\
\hline 20 & 1255 & 0.5 & 0.5 \\
\hline 20 & 1255 & 0.5 & 1.0 \\
\hline 20 & 1255 & 0.5 & 1.6 \\
\hline 30 & 1255 & 1.0 & 0.5 \\
\hline 30 & 1255 & 1.0 & 1.0 \\
\hline 30 & 1255 & 1.0 & 1.6 \\
\hline 50 & 1255 & 1.5 & 0.5 \\
\hline 50 & 1255 & 1.5 & 1.0 \\
\hline 50 & 1255 & 1.5 & 1.6 \\
\hline 20 & 2000 & 0.5 & 0.5 \\
\hline 20 & 2000 & 0.5 & 1.0 \\
\hline & & & \\
\hline & & & \\
\hline
\end{tabular}




\section{Journal of Student Research}

Fourth Middle East College Student Research Conference, Muscat, Sultanate of Oman

\begin{tabular}{|l|l|l|l|}
\hline 20 & 2000 & 0.5 & 1.6 \\
\hline 30 & 2000 & 1.0 & 0.5 \\
\hline 30 & 2000 & 1.0 & 1.0 \\
\hline 30 & 2000 & 1.0 & 1.6 \\
\hline 50 & 2000 & 1.5 & 0.5 \\
\hline 50 & 2000 & 1.5 & 1.0 \\
\hline 50 & 2000 & 1.5 & 1.6 \\
\hline
\end{tabular}

Table 2. The experimental tests

\section{Results}

Tables 3, 4, and 5 below show the results for different experimental sets and shaft diameters.

\begin{tabular}{|l|l|l|l|l|l|}
\hline$\#$ & L9 sets & Ra1 & Ra2 & Ra3 & Aveg. \\
\hline 1 & 111 & 4.23 & 4.56 & 4.57 & 4.45 \\
\hline 2 & 122 & 4.99 & 5.32 & 4.37 & 4.89 \\
\hline 3 & 133 & 4.42 & 6.40 & 5.10 & 5.31 \\
\hline 4 & 212 & 2.92 & 4.01 & 2.29 & 3.06 \\
\hline 5 & 223 & 2.83 & 2.91 & 3.31 & 3.02 \\
\hline 6 & 231 & 3.92 & 3.81 & 3.73 & 3.82 \\
\hline 7 & 313 & 1.31 & 1.34 & 1.26 & 1.76 \\
\hline 8 & 321 & 1.87 & 1.75 & 1.42 & 1.79 \\
\hline 9 & 332 & 1.25 & & 1.37 \\
\hline
\end{tabular}

Table 3. The results of the surface roughness for shaft diameter $(20 \mathrm{~mm})$

\begin{tabular}{|l|l|l|l|l|l|}
\hline$\#$ & L9 sets & Ra1 & Ra2 & Ra3 & Aveg. \\
\hline 1 & 111 & 4.12 & 3.87 & 4.73 & 4.24 \\
\hline 2 & 122 & 1.92 & 1.51 & 2.08 & 1.81 \\
\hline 3 & 133 & 2.16 & 2.85 & 1.82 & 1.94 \\
\hline 4 & 212 & 4.74 & 3.41 & 3.96 & 4.04 \\
\hline 5 & 223 & 2.10 & 2.32 & 2.15 & 2.19 \\
\hline 6 & 231 & 2.80 & 3.07 & 4.00 & 3.29 \\
\hline 7 & 313 & 1.04 & 0.98 & 0.97 & 0.99 \\
\hline 8 & 321 & 1.81 & 1.91 & 1.81 & 1.84 \\
\hline 9 & 332 & 1.61 & 1.75 & 1.63 & 1.66 \\
\hline
\end{tabular}

Table 4. The results of the surface roughness for shaft diameter $(30 \mathrm{~mm})$

\begin{tabular}{|l|l|l|l|l|l|}
\hline$\#$ & L9 sets & Ra1 & Ra2 & Ra3 & Aveg. \\
\hline 1 & 111 & 4.53 & 5.94 & 6.02 & 5.50 \\
\hline 2 & 122 & 1.32 & 1.55 & 1.38 & 1.42 \\
\hline 3 & 133 & 1.43 & 1.51 & 1.39 & 1.44 \\
\hline 4 & 212 & 1.06 & 0.81 & 0.94 & 0.93 \\
\hline 5 & 223 & 1.49 & 1.50 & 1.42 & 1.47 \\
\hline 6 & 231 & 1.10 & 1.13 & 1.18 & 1.13 \\
\hline 7 & 313 & 1.21 & 1.12 & 1.07 & 1.35 \\
\hline 8 & 321 & 1.44 & 1.61 & 1.91 & 1.53 \\
\hline 9 & 332 & 1.88 & 2.48 & & 2.10 \\
\hline
\end{tabular}

Table 5. The results of the surface roughness for shaft diameter $(50 \mathrm{~mm})$

\section{Discussion}

The total results obtained using the statistical software Minitab 14.0 and Taguchi L9. The results 
show that the speed is one of most important component of cutting parameters where high speed 2000 RPM lead to smoother surface comparing to the lower speed.

Figure 1 shows the main effect plot for means of the surface roughness and how it is affected by the cutting parameters (Speed, Feed Rate, and Depth of Cut) and the shaft diameter as well. It is clearly shows that the surface roughness affected mainly by the cutting speed and shaft diameter and high speed and bigger diameter give better surface roughness.

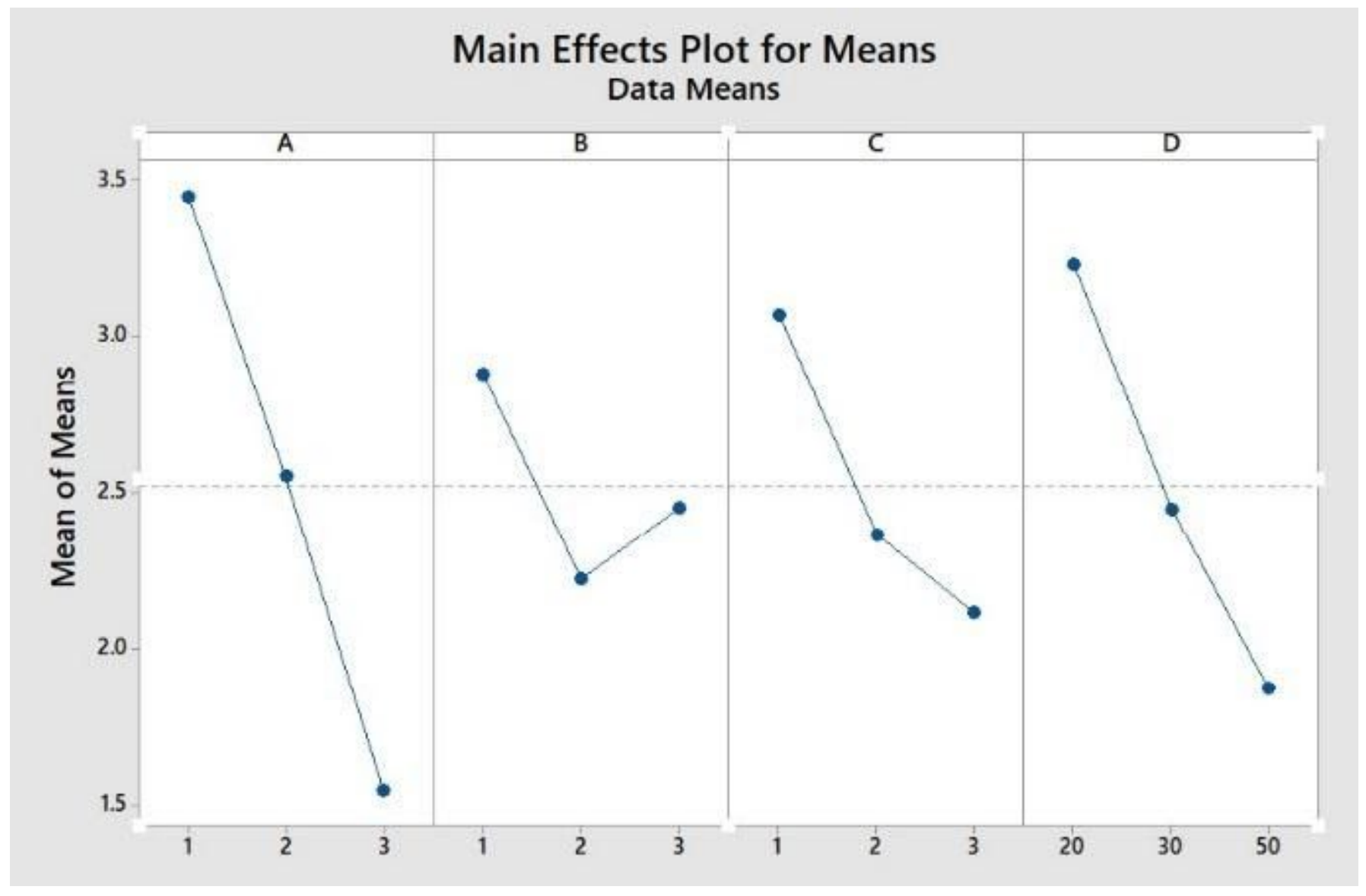

Figure 1. Main effects plot for means.

\section{Conclusion}

In this research an introduction about cutting parameter optimization and the factors affect the surface quality in turning operation were presented with some relative literature review. The main objective of this research was the study of the effect of workpiece diameter on the surface quality. In this study the result shows the shaft diameter effect quality of workpiece surface in addition to the cutting speed and the researchers should take into account this effect when compare this results for such relative cases.

\section{Acknowledgements}

The authors want to acknowledge the mechanical engineering department at Middle East College for providing the necessary equipment and materials during the development of this research, the experimental setup would not been realized without the department full support.

\section{References}


Bhuiyan, T.H. and Ahmed, I., 2014. Optimization of Cutting Parameters in Turning Process. SAE International Journal of Materials and Manufacturing, 7(1), pp.233-239.

Dejan T. (2010, February 19). Modelling and Optimization of the Surface Roughness in the Dry Turning of the Cold Rolled Alloyed Steel Using Regression Analysis. Retrieved from:

http://www.scielo.br/pdf/jbsmse/v34n1/v34n1a06.pdf

Suhail, A. H., Ismail, N., Wong, S. V., Abdul Jalil N. A., 2010, Optimization of Cutting Parameters Based on Surface Roughness and Assistance of Workpiece Surface Temperature in Turning Process. Retrieved from: https://www.freelancejob.ru/upload/683/33280283305794.pdf

Sahu, P.K., Sahu, N.K. and Dubey, A., 2017. Optimization of Cutting Parameters by Turning Operation in Lathe Machine. International Multidisciplinary Conference on Emerging Trends in Engineering, Science and Technology, pp.69-74 